\title{
Clinical Review: Best Medical Therapy Superior to Carotid Endarterectomy in Secondary Stroke Prevention in Symptomatic Extracranial Internal Carotid Artery Stenosis of $50-69 \%$
}

ISSN: 2639-0531

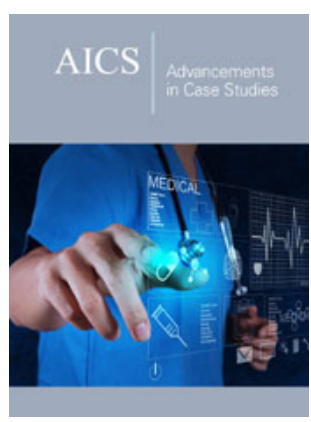

*Corresponding author: Blaine C, College of Medicine, USA

Submission: 䤈 December 16, 2019

Published: 些 January 07, 2020

Volume 2 - Issue 3

How to cite this article: Blaine $\mathrm{C}$, $\mathrm{Chu} \mathrm{M}$, Elsabee M, Downs A, Naqvi A, et al. Clinical Review: Best Medical Therapy Superior to Carotid Endarterectomy in Secondary Stroke Prevention in Symptomatic Extracranial Internal Carotid Artery Stenosis of $50-69 \%$. Adv Case Stud.2(3) AICS.000536.2020

DOI: $10.31031 /$ AICS.2020.02.000536

Copyright@ Blaine C, This article is distributed under the terms of the Creative Commons Attribution 4.0 International License, which permits unrestricted use and redistribution provided that the original author and source are credited.

\author{
Blaine C*, Chu M, Elsabee M, Downs A, Naqivi A, Acosta A and Lui F \\ College of Medicine, USA
}

\begin{abstract}
Extracranial internal carotid artery stenosis poses a high risk of recurrent stroke or transient ischemic attack (TIA) after a TIA or minor stroke. Secondary prevention with carotid endarterectomy for highgrade stenosis between $70-99 \%$ has been well documented with large scale randomized controlled trials in both Europe and North America. The benefit of intermediate grade stenosis (50-69\%) stenosis is not as clear and the present-day standard treatment guidelines do not favor surgery or best medical treatment. When the surgery trials were published in early 1990 s, the medical therapy was not as clear or as aggressive. Over the past $20+$ years, multimodality medical therapy has been strongly recommended in all stroke guidelines and significantly improved results of secondary prevention of $80-90 \%$ is achievable. This review will try to analyze the available data to provide the best treatment recommendation for patients with symptomatic extracranial internal carotid stenosis of 50-69\%.
\end{abstract}

\section{Introduction}

Transient ischemic attacks (TIA) are known as a herald to an impending stroke or another TIA. Past medical assessment of the risk of stroke following a transient ischemic attack (TIA) commonly quoted a 1-2\% risk of stroke at seven days following a TIA and $2-4 \%$ risk of stroke at one-month following a TIA [1]. However, current literature indicates that these values underestimate the risk of stroke in TIA patients. Newer data indicate that the current risks for stroke following a TIA are approximately $8 \%$ at seven days and $11.5 \%$ at one-month after TIA [2]. Identifying patients most at risk for stroke following TIA is crucial to initiate the most beneficial intervention. This can be done by identifying key risk factors highly associated with stroke rate such as age greater than 60 years old, diabetes mellitus, symptom duration over 10 minutes, weakness, speech impairment [3].

Another major risk to the recurrence of a cerebrovascular event after a TIA or minor stroke is internal carotid stenosis. But implementing the proper therapy for this stenosis takes consideration. Previous studies have shown that surgical intervention outweighs the benefits of medical intervention in prevent the recurrent of ipsilateral cerebral ischemic events with patients who have high grade stenosis (70-99\% occlusion) of the extracranial internal carotid artery [4]. Carotid endarterectomy and carotid stenting are the main surgical interventions and have been shown to be statistically similar in benefit when performed by surgeons with a high level of expertise; however, the perioperative complications change based on the patient's age and gender [5]. Surgical therapy has also been shown to have increased risk of adverse events with lower efficacy of preventing recurrence for stenosis less than 50\% [6]. However, the best treatment for patients with stenosis of $50-69 \%$ of the extracranial internal carotid artery is still controversial.

\section{Objective}

Our objective was to analyze the current literature available to determine if surgical intervention is superior to best medical therapy in preventing recurrence of stroke in patients 
with $50-69 \%$ stenosis of the extracranial internal carotid artery. Best medical therapy includes strict control of blood pressure, high dose statin therapy, stricter blood glucose control, quitting smoking, healthy lifestyle and diet, regular exercise and appropriate antithrombotic treatment.

\section{Methods}

We performed a thorough review of the available literature covering current stroke guidelines from the American Heart Association as well as relevant data regarding surgical and medical therapy for recurrent strokes from The New England Journal of Medicine, The Lancet, Stroke, and Journal of the American Medical Association. Our analysis covered literature from 1991 to 2018.

\section{Results}

The North American Symptomatic Carotid Endarterectomy Trial Collaborators (NASCET) first published the result of a study in 1991 to compare medical and surgical therapies in treating the recurrence of cerebrovascular events based on a patient's degree of carotid stenosis. These early data were based on high grade stenosis as that portion of the trial was concluded early as surgical intervention was clearly superior [4]. It would be several more years until the data for moderate stenosis (50-69\% occlusion) would be released in 1998. These results showed patients with symptomatic stenosis of 50-69\% of the extracranial internal carotid artery had an ipsilateral stroke in $22.2 \%$ of medically treated patients and $15.7 \%$ of surgically treated patients after 5 years. This is a $29 \%$ relative risk reduction. However, the medical therapy described in that trial consisted of anti-thrombo-tics, mostly in the form of aspirin, and hypertension and hyperlipidemia medications "when indicated." The efficacy of these medical therapies was not well document in the results. Even this early result notes, though, that rates of recurrence after beginning surgical or medical therapy become equal after approximately 2 years after initiating therapy. Surgery then provides a better window of protection from the high risk 90 day window after a TIA until 2 years after the event. It should be noted that it is within 2-5 years after a TIA or minor stroke that the majority of strokes will occur [7].

Similar results can be seen in the European Carotid Surgery Trialists' results from a contemporary study in 1998 [5]. Their studies only showed a $16 \%$ relative risk reduction between surgery and medical therapy which was absent in women who also had a higher risk of perioperative complications. The ECST similarly showed aspirin as the major medical therapy with a relative minority of patients on other medications including lipidlowering agents. There was no mention of diabetic control or use of antihypertensive agents.

It should be emphasized that surgical therapy had no statistically significant benefit for women compared to medical therapy and had greater risk due to perioperative complications [6-8]. Arijana et al. [9] in their review article on management of patients with carotid stenosis also pointed out that the number needed to treat (NNT) by CEA to prevent one ipsilateral stroke in 5 years was 9 for men versus 36 for women [9]. This has likewise been seen even with asymptomatic patients [10]. Several new protocols with stronger medications and stricter goals have been established since the NASCET trials were completed which include combination antithrombotic therapies, antihypertensives, and statins $[11,12]$.

Best multimodality medical therapy trials begin to muddy the conclusions of the NASCET and ECST results. The ACCORD blood pressure study was performed in diabetic TIA patients who have a high risk of recurrence of another cerebrovascular event [13]. The trial divided the group into standard therapy which required systolic blood pressure control under $140 \mathrm{mmHg}$ or an intensive therapy which required systolic blood pressure control under $120 \mathrm{mmHg}$. The predicted 5-year recurrence rate of any stroke after a cardiovascular event was $1.6 \%$ in the intensive therapy and $2.65 \%$ in the standard therapy. However, the conditions of the enlisted participants only dictated that they be diagnosed with "anatomical evidence of substantial amounts of atherosclerosis" without specifying the level of carotid stenosis, if any.

A view of more comprehensive medical therapy comes from a metanalysis performed by Daniel \& David [14]. Their study analyzed the effect of medical therapy using antihypertensives, lipid-lowering drugs, anti-thrombotic, good diabetic control, and lifestyle changes including diet, exercise, and smoking cessation [14]. Their calculated risk for a patient having a recurrent cerebrovascular event within 5 years was $24.4 \%$ which was reduced to $4.8 \%$ with treatment. They predicted further reduction to $2.8 \%$ recurrence with an intensive therapy approach which consisted of diet, exercise, aspirin or dipyridamole, high dose statins, and aggressive blood pressure lowering. They also noted that patients with high grade stenosis $(70-99 \%$ occlusion) would receive a similar $90 \%$ relative risk reduction with carotid endarterectomy along with the best medical therapy. In the same year, the UK EXPRESS Study in Oxford, England published by Rothwell et al. [15] also showed similar findings with stroke risk reduction of $80 \%$ by using multimodality medical treatment with anti-thrombo-tics, statin, and intensive BP control, and lifestyle modification [15]. In review of the literature, outcomes of surgery clearly correlate with the experience of the surgeons yet there is no correlation between different racial groups [16].

While surgical intervention is an important part of comprehensive medical therapy in cases of high-grade stenosis, the overall use of surgical interventions has decreased dramatically over the past 20 years. Surgical intervention in the treatment of carotid stenosis decreased by over 20\% between 1998 and 2008 [17]. While there was a notable increase in carotid artery stenting (CAS) in 2006, this was largely attributed to a temporary Medicaid expansion in 2005 [18]. This expansion only lasted for one year, after which the number of CAS procedures performed returned to 2004 levels.

\section{Discussion}

Early surgical trials showed patients with symptomatic stenosis $50-69 \%$ of the extracranial internal carotid artery had better outcomes within 2 years of their operation, then 
were equivalent with medical therapy. However, women had no statistical benefits from surgery and were at greater risk for perioperative complications. Since the surgical trials were first conducted, medical therapies have become more comprehensive, more aggressive, and more effective than what the early trials were using. Later meta-analysis shows aggressive medical therapy to be equivalent to surgical interventions in high grade stenosis which is known to have the greatest benefit from surgery. While the decline in number of surgeries performed does not speak directly to the efficacy or safety of these surgeries, we believe that part of this decline is due to the rise of improved medical therapies that eroded the need for surgical interventions.

\section{Conclusion}

We conclude that symptomatic patients with extracranial internal carotid artery stenosis of 50-69\% should be managed with best medical therapy rather than surgical intervention to prevent the recurrence of stroke, especially with female patients. The SAMMPRIS II trial which is currently ongoing is testing a similar hypothesis and will have further evidence to confirm or refute these conclusions in 2020 ..

\section{References}

1. Lovett JK, Dennis MS, Sandercock PA, Bamford J, Warlow CP, et al. (2003) Very early risk of stroke after a first transient ischemic attack. Stroke 34(8): e138-e140.

2. Coull AJ, Lovett JK, Rothwell PM (2004) Population based study of early risk of stroke after transient ischemic attack or minor stroke: Implications for public education and organisations of services. BM] 328(7435): 326.

3. Johnston SC, Gress DR, Browner WS, Sidney S (2000) Short-term prognosis after emergency department diagnosis of TIA. Jama 284(22): 2901-2906.

4. North American Symptomatic Carotid Endarterectomy Trial Collaborators (1991) Beneficial effect of carotid endarterectomy in symptomatic patients with high-grade carotid stenosis. N Engl J Med 325(7): 445-453.

5. Brott TG, Hobson RW, Howard G, Roubin GS, Clark WM, et al. (2010) Stenting versus endarterectomy for carotid-artery stenosis. N Engl J Med 363(1): 11-23
6. Barnett HJM, Taylor D, Eliasziw M, Fox AJ, Ferguson GG, et al. (1998) Benefit of carotid endarterectomy in patients with symptomatic moderate or severe stenosis. N Engl J Med 339(20): 1415-1425.

7. Amarenco P, Tavares LM, Labreuche J, Albers GW, Abboud H, et al. (2018) Five-Year risk of stroke after TIA or minor ischemic stroke. New England Journal of Medicine 379(16): 1579-1581.

8. European Carotid Surgery Trialists' Collaborative Group (1998) Randomised trial of endarterectomy for recently symptomatic carotid stenosis: Final results of the MRC European Carotid Surgery Trial (ECST). Lancet 351(9113): 1379-1387.

9. Lovrencic HA, Rundek T, Katsnelson M (2012) Recommendations for management of patients with carotid stenosis. Stroke Res Treat 2012: 175869 .

10. Rothwell P, Goldstein L (2004) Carotid endarterectomy for asymptomatic carotid stenosis. Stroke 35(10): 2425-2427.

11. Kernan WN, Ovbiagele B, Black HR, Bravata DM, Chimowitz MI, et al. (2014) Guidelines for the prevention of stroke in patients with stroke and transient ischemic attack. Stroke 45(7): 2160-2236.

12. Powers W, Rabinstein A, Ackerson T, Adevoe O, Bambakidis N, et al. (2018) 2018 guidelines for the early management of patients with acute ischemic stroke: A guideline for healthcare professionals from the American heart association/American stroke association. Journal of Vascular Surgery 67(6): 1934.

13. Cushman WC, Evans GW, Byington RP, Goff DC, Grimm RH, et al. (2010) Effects of intensive blood-pressure control in type 2 diabetes mellitus. $\mathrm{N}$ Engl J Med 362(17): 1575-1585.

14. Hackam DG, Spence JD (2007) Combining multiple approaches for the secondary prevention of vascular events after stroke. Stroke 38(6): 1881-1885.

15. Rothwell PM, Giles MF, Chandratheva A, Marquardt L, Geraghty O, et al. (2007) Effect of urgent treatment of transient ischaemic attack and minor stroke on early recurrent stroke (EXPRESS study): A prospective population-based sequential comparison. Lancet 370: 1432-1442.

16. Yang L, Liu J, Qi G, Li Y, Liu Y (2018) The middle-term outcome of carotid endarterectomy and stenting for treatment of ischemic stroke in Chinese patients. Sci Rep 8(1): 4697.

17. Skerritt MR, Block RC, Pearson TA, Young KC (2012) Carotid endarterectomy and carotid artery stenting utilization trends over time. BMC Neurol 12: 17.

18. Lichtman JH, Jones MR, Leifheit EC, Sheffet AJ, Howard G, et al. (2017) Carotid Endarterectomy and Carotid Artery Stenting in the US Medicare Population, 1999-2014. JAMA 318(11): 1035-1046. 